\title{
Are Discount Rates In Disarray In The First Year Adoption Of International Financial Reporting Standards?
}

\author{
Manh Dung $\operatorname{Tran}^{1 *}$, Thu Thuy Nguyen ${ }^{2}$ \\ ${ }^{1}$ National Economics University, Vietnam \\ ${ }^{2}$ Thuongmai University, Vietnam
}

Corresponding author: manhdung@ktpt.edu.vn

Received: 07, April, 2021

Accepted: 14, April, 2021

Published: 15, April 2021

\begin{abstract}
In calculating recoverable amount of cash generating units (CGUs) under the implementation of value in use approach, discount rate selection represents a central point in deciding the magnitude of impairment charges under Hong Kong Financial Reporting Standards (HKFRSs). The selection of discretion discount rate in the discounted cash flow model (DCF) could be used opportunistically to misstate impairment losses for the benefit of financial statement preparers and causes the transparency of the financial reports. This study is conducted to provide evidence of opportunistic behaviours relating on goodwill impairment by reporting statement preparers. By comparing independently estimated risk adjusted discount rates and those subjectively presented by large listed Hong Kong firms in the first year adoption of HKFRSs, the results showed that discount rates were presented in disarray, in which discount rates were more overstated than understated in comparison with scientifically generated ones.
\end{abstract}

Keywords: Goodwill, Financial Reporting, Impairment Accounting, Hong Kong

\section{Introduction}

Goodwill has been the most controversial issue in many countries all over the world (Seetharaman et al., 2004) . One of the early definitions of goodwill can be found in the "A Counting House Dictionary", where goodwill is defined as a willingness of an owner of a business to relinquish the expectation of the business by transferring it for a consolidation to someone else. Goodwill has been depicted as unreliable and undesirable.

With the nature of intangible rather than tangible asset, goodwill was considered to be fickle and there was confusion in recording, measuring and reporting it (Canning, 1929). After many years of commentary and analysis, goodwill is still as the black sheep of the balance sheet in the financial statements (Carlin et al., 2007).

Due to intangible nature of goodwill and many ways to defining it, substantial changes in accounting and reporting are also easy to understand. Specifically, through time and across a range of jurisdiction, a tangled web of contradictory of goodwill has been prescribed in the accounting standard (Carlin and Finch, 2008). The reason to exist different goodwill treatments is that the level of goodwill perception is also different when the time passed.

For accounting perspective, some treatments of goodwill have been conducted by reporting firms, i.e. requirements to write off (eliminate) completely against an account in shareholder's equity, reserve or retained earnings, requirements that goodwill be capitalised and not written off at all unless no strong evidence, requirements that goodwill be capitalised and amortised systematically over a reasonable period of time, requirements that goodwill be capitalised and impaired (Seetharaman et al., 2004; Carlin \& Finch, 2008).

In the circumstance of Hong Kong pertaining to this issue, the debate over how to account for goodwill and intangible asset has been going on for a long time. The mandatory annual amortisation of goodwill against retained earnings has been removed and new method of goodwill impairment has been applied based on many assumptions. Adoption of goodwill impairment method has been opened the new chapter after having contradictory treatments of goodwill. However, it is admitted that in the early years of application this standard, financial statement preparers face to cope with new and challenge issue, goodwill impairment.

At the early period of applying method of impairment testing under HKFRS, considerable concern about validity and principle basis has been existed from the practitioner's perspective (Lonergan, 2007). In the context of goodwill impairment standard, there are two methods prescribed to calculate asset recoverable amount, fair value less cost to sell and value in use and which method to be applied depends on each company.

In investigating the method of value in use for calculating asset recoverable amount, many assumptions should be given, including discount rate, growth rate, forecast period. Each of these 
assumptions has potential impact on the robustness and outcomes of impairment testing regime conducted by reporting companies.

In adoption the method of value in use, discounted cash flow model is considered to be high reliance for estimating recoverable amount. In this model, discount rate plays very important part and assumes the crucible variable for transforming future cash flow to present value. According to Carlin and Finch (2008), present value of cash flow can be highly sensitive even to small variations of discount rates over the forecast period.

Accordingly, this research provides evidence on the discount rate selection for the purposes of goodwill impairment testing and on the degree that asset impairment regimes are flawed in the aspects of giving financial statement preparers a fertile ground in exercising discretion of goodwill impairment. By doing this research, comparison technique has been used between observed discount rates applied by reporting firms and independently estimated discount rates. Also through this research, opportunistic behaviour can be proved pertaining to recording, measuring and reporting of goodwill impairment.

\section{Literature review and theoretical framework}

Goodwill has been first existed in the legal accounting framework of Statement Standard Accounting Practice (SSAP) 1 "Presentation of Financial Statements" issued by HKSA in March 1984. Between 1984 and 2004, the method "capitalise and amortise" for goodwill reporting operated on the basis of the assumption that the useful life of goodwill was finite, usually not exceeding twenty years from initial recognition. However, the commencing assumption of the IFRS about goodwill is that goodwill renders economic benefits and its period is understood to be indefinite (Carlin and Finch, 2008).

For the convergence with IFRSs, Hong Kong has constructed an own version of accounting framework came into effect from 1st January, 2005, mainly based on IFRSs (Hui \& Ng, 2006; E\&Y, 2008). In this situation, the "amortise of goodwill method" was superseded by impairment testing regime based on many subjective and ambiguous assumptions. Goodwill accounting standards require reporting companies to capitalise goodwill, recognise impairment charges, record expenses in the income statement in case of CGU recoverable amounts lower than CGU carrying values.

For determining whether nor not impairment expense exists, some steps should be applied such as identify individual asset or group of assets, estimated future cash inflows, choose appropriate discount rate, determine recoverable amount and write down carrying amount to recoverable amount (Hui \& Ng, 2006).

In the sense of accounting framework, recoverable amount should be estimated for the individual asset if there is any indication that an asset may be impaired. Otherwise company should determine the recoverable amount of CGU to which the asset belongs. A CGU is defined as the smallest identifiable group of assets that produces cash inflows that are largely independent of the cash inflows from other assets or groups of assets.

Value of assets associated with CGUs have known as carrying amount (accounting book value), so the book value of a CGU consists of the sum of the book values of individual assets in that group and all those assets together generated cash inflows that are independent of the cash inflows from others. Carrying amount is understood as the amount at which an asset is recognized after deducting any accumulated depreciation (amortization) and accumulated losses. If the company has goodwill, there may have at least one CGU even though many CGUs exist. However, in the process of appropriate CGU aggregation the standard prescribes that each CGU to which the goodwill is so allocated shall not be larger than a segment determined in the the standard of segment reporting.

Goodwill naturally does not produce cash flows independently from other assets or groups of assets, so goodwill should be allocated to each of CGUs that are expected to benefit from the synergies of the acquisition when the number of CGUs was defined by the company. After having the CGU carrying amount and value that goodwill allocated to its CGU, goodwill impairment testing should be conducted for calculating CGU recoverable amount. Of course, the time to test goodwill impairment depends on each company.

Then values of CGU recoverable amounts are compared with known CGU book values. If CGU recoverable amount is higher than its carrying amount, there is no impairment charge. Otherwise goodwill impairment is existed, and then CGU book value is required to write down to recoverable amount. Impairment expense is attributed first to any goodwill allocated to that CGU and then to the other assets of the unit pro-rata on the basis of the carrying amount of each asset in the CGU.

As requirements in the prevailing accounting standards, there are two methods to be used for calculating recoverable amount of CGU, namely, fair value less cost to sell and value in use. Recoverable amount of CGU is understood as the higher of fair value less cost to sell and value in use. Theoretically, the entity can apply both method (fair value and value in use) to calculate CGU recoverable amount and then compare to decide the higher value for recoverable amount or choose only method of fair value (if active market exists) or value in use. However, in the extant research, majority of companies chose method of value in use to calculate CGU recoverable amount rather than fair value or mixed method.

In order to calculate CGU recoverable amount in value in use approach, model of discounted cash flow should be designed based on the assumptions prescribed in the accounting standard, including estimated cash inflows, the appropriate discount rates. Paragraph 134 of HKAS 36 prescribes provisions designed to denote transparent of key inputs and assumptions in the model of discounted cash flow for calculating CGU recoverable amount.

In the model of discounted cash flow, discount rate plays very important part in calculating recoverable amount of CGUs. Discount rate that was misstated (overstated or understated) to substantially affect to recognizing impairment losses. Discount rates employed for the purposes of transforming CGU future cash flow value to their present values are required to assign to the risk characteristics of each CGU.

However, extant studies reveal that there are many entities disclosed the single discount rates as components to calculate recoverable amount of all CGUs. Previous studies also have investigated the compliant level and disclosure quality for having insights of goodwill impairment, including discount rate. However, discount rate investigation was somewhat limited in those studies. For that reason, doing this research has purpose of comparing the observed discount rates employed by companies in the impairment testing process and independently estimated discount rates.

Due to high number of firms define only one discount rate (single discount rate) for all CGUs regardless each CGU has different risk characteristics, so it is feasible to do this research. It turns out that analytical procedure is conducted to compare the "whole firm" observed discount rate and "whole firm" estimated discount rate. 
In case where reporting firms define multiple CGUs and assign different discount rates to each CGU (multiple discount rates), the undertaking comparable analysis considers to be very difficult because there is of the greater degree of challenge in estimating discount rates applicable to parts of business, rather than the whole business. In other case when companies assume the range of discount rates for CGUs, it is not parallel to compare the specific estimated discount rate with the range of discount rate. So this research only concentrates discount rates set by companies which applied single discount rates for all CGUs in the process of testing goodwill impairment.

In the process of comparing independent estimated discount rates and observed ones, two possibilities may be existed. In case of small difference between them is accepted, the notion of opportunism in undertaking goodwill impairment may be eliminated when firms approach the standard requirements. Otherwise, substantial differences between them may provide evidence consistent with opportunism in recording, measuring and reporting goodwill impairment.

\section{Research methodology}

\subsection{Data collection}

Hong Kong Financial Reporting Standards (HKFRSs) for all reporting entities to apply on or after 1st January 2005. Consequently, a subset of the listed Hong Kong companies reported in compliance with HKFRSs in that year. However, the period of financial year lasts twelve months, so only entities to do so were those with balance sheet date at 31 st December, being the first year firms to adopt HKFRSs.

The process of building the research sample was structured as follows. First, companies were required to be the members of Hong Kong Stock Exchange (HKEx) as at year end of the first year adoption. There were 934 companies with total market capitalisation of 8,113 billion HK\$. Then 500 biggest market value companies with 8,026 billion HK\$ (accounting for 98.94\% market capitalisation) were chosen. Companies were included in the research sample if they had goodwill balances, issued financial statements in compliance with HKFRSs. Consequently, this process constructed a commencing sample of 161 companies with market value of 4,431 billion HK\$, representing $54.61 \%$ of total market capitalisation in HKEx at the end of the first year adoption of HKFRSs.

Of these 161 reporting firms in the commencing sample, we select 86 companies which used the method of value in use to test goodwill impairment by calculating CGU recoverable amounts and defined only one single discount rate.

\subsection{Research approach}

In order to compare the single discount rates disclosed by sample companies and independently estimated discount rates. It was necessary to make sure that all discount rates disclosed had been expressed on a comparable basis, pre-tax discount rate. Paragraph 66 of HKAS 36 stipulates that the discount rate shall be a pre-tax rate that denotes current market assessment of the time value of money and the risk specific to the CGUs. Despite of having this requirement, one entity in the final sample still disclosed post-tax discount rate rather than pre-tax discount rate. This was converted to pre-tax equivalent discount rate by dividing it by one minus the prevailing corporate income tax.

The Capital Asset Pricing Model (CAPM) was employed to develop independent discount rate estimations for the purposes of comparing with companies discount rate disclosure. This model is viewed the preferred method to estimate an appropriate discount rate because it represents the current market assessment and the risks specific to the CGU asset of the company (Carlin and Finch, 2008). Using the technique of CAPM is also applicable to the requirements prescribed in HKAS 36 that discount rates applied should be assets specific in term of risks and independence of financing considerations. As a starting point in marking discount rate estimation, using this technique (CAPM) is consistent with huge evidence suggesting that it is the dominant method employed by companies in the estimation of their cost of capital.

With the purpose of comparison between estimated and observed discount rates for each entity in the sample, some steps were conducted as below.

First, levered beta or geared beta $(\beta \mathrm{L})$ : The levered beta for each firm was collected from Datastream at the year-end 2005. The Datastream provides international financial, economic, stock market and company data. The beta measures each entity's stock price sensitivity to fluctuations of the market as a whole. Beta is considered to be a key parameter in the CAPM (Fernandez, 2003).

Second, unlevered beta or ungeared beta $(B U)$ : The unlevered beta for each company was calculated by using the equation of Hamada (1972).

$\beta_{\mathrm{U}}=\beta_{\mathrm{L}} / 1+(\mathrm{D} / \mathrm{E}) *(1-\mathrm{t})$. Where:

$\beta_{U} \quad$ : the unlevered asset beta of the company

$\beta_{\mathrm{L}} \quad$ : the levered beta of the company

$\mathrm{D} / \mathrm{E} \quad$ : the book value leverage ratio of the entity

$\mathrm{t}$ : entity marginal tax rate, being $17.5 \%$

Third, the expected after tax rate of return specific to the firm's assets (ra): ra can be calculated from the CAPM as below.

$r_{a}=r_{f}+\beta_{U} *\left(r_{m}-r_{f}\right)$. Where:

ra : the expected after tax rate of return specific to the firm's assets

rf $\quad:$ the long-term risk free rate

BU : the unlevered asset beta of the company

rm - rf : the market risk premium for equity shareholders

The long term risk free rate $\left(\mathrm{r}_{\mathrm{f}}\right)$ assumes a value of $3.65 \%$ being the Hong Kong government 10 year bond market yield at December 2005.

The expected market risk premium for equity shareholders $\left(r_{m}-r_{f}\right)$ assumes a value of $6 \%$. This figure is consistent with the findings of Gameiro (2008) using data for the period from 1995 to 2008 and also suitable to the range of average market risk premium in some literature (Song, 2007; Gameiro, 2008).

Finally, pretax discount rate (rb): The pretax discount rate is calculated by using the expected after tax rate of return specific to the entity's asset (ra) divides the value of 0.82 , being 1 minus the entity tax rate of $17.5 \%$.

After having the estimated discount rate for each company in sample, comparison between estimated and observed discount rate was conducted. The variance between them was calculated and stratified on an industry classification, goodwill intensity and basic points of each company.

In terms of industry classification, Hang Seng Industry Classification System was employed. It consists of 11 industries that meet the need for a detailed industry classification and reflects stock performance in different sectors.

Goodwill intensity is defined as a measure of the sensitivity of sample entity reported profits to goodwill impairment losses (Carlin and Finch, 2008), and is measured by using equation:

Goodwill Intensity = Goodwill Balance/Net Profit Before 
In terms of goodwill intensity, some instances can be existed:

First, goodwill intensity is higher than 1 : This case suggests that there is a high degree of sensitivity to the current loss as a result of an impairment charge. The higher the value of goodwill intensity is, the greater the risk of losses is in the current period. In the dimension of this research, goodwill intensity is classified in some categories, including some ranges from 1 to 2,2 to 3,3 to 4,4 to 5 and higher than 5 .

Second, goodwill intensity is from 0 to 1 : This instance suggests a lower degree of sensitivity to a write-down profit in the current period as a result of an impairment expense.

Third, goodwill intensity is lower than 0: This case implies that the company has loss and any impairment charges will increase more losses in the current period.

In order to facilitate the comparison between independently estimated discount rates and observed discount rates, a system of basis points (bps) has been constructed. Basic points were calculated based on the independently estimated discount rates and divided into 5 ranges. This system includes the ranges of "within expected range" (from minus $150 \mathrm{bps}$ to plus $150 \mathrm{bps}$ around expectation), " 150 to 250 bps above expectation", "higher than 250 bps above expectation", "150 to 250 bps below expectation" and "higher than 250 bps below expectation".

\section{Results and Discussion}

This research investigates variation between independently estimated and observed disclosed discount rates applied for the purposes of goodwill impairment testing. Data collected and results of this research also strengthened the findings of other studies on disclosure quality and compliant level by testing goodwill impairment. As stated in the previous section, the precondition is that each company in sample only applied single discount rate (the same discount rate for all CGUs). It means that the reporting firm supposes the same risk characteristics of all CGUs even though HKAS 36 states that discount rates employed should relate to the underlying risk characteristics of each defined CGU.

Table 1: Number of Defined CGUs by Sectors

\begin{tabular}{|c|c|c|c|c|c|c|c|c|}
\hline Sectors & No. of firms & No disclosure & 1CGU & 2CGUs & 3 CGUs & 4CGUs & 5 CGUs & $>5$ CGUs \\
\hline Conglomerates & 3 & 1 & 1 & - & - & - & - & 1 \\
\hline Consumer Goods & 19 & 3 & 10 & 3 & 2 & - & - & 1 \\
\hline Energy & 2 & - & - & 1 & - & 1 & - & - \\
\hline Financials & 8 & - & 4 & - & 2 & 1 & 1 & - \\
\hline Industrial Goods & 8 & 3 & 2 & 2 & 1 & - & - & - \\
\hline Information Technology & 5 & 1 & 1 & 2 & 1 & - & - & - \\
\hline Materials & 4 & 1 & 1 & 1 & 1 & - & - & - \\
\hline Properties \& Construction & 10 & - & 6 & 3 & 1 & - & - & - \\
\hline Services & 20 & 2 & 8 & 5 & 2 & 1 & 1 & 1 \\
\hline Telecommunications & 1 & 1 & - & - & - & - & - & - \\
\hline Utilities & 6 & - & 2 & 2 & 1 & - & - & 1 \\
\hline Total & 86 & 12 & 35 & 19 & 11 & 3 & 2 & 4 \\
\hline
\end{tabular}

Source: Authors' compilation

If the entity has only one CGU and goodwill is associated with that goodwill, only single discount rate will be presented for the purpose of meeting requirements of the standard. As data in Table 1 shows clear that about two fifth companies in sample defined only one CGU (accounting for $40 \%$ in total sample). There is a negative relationship between the number of companies and the number of CGUs defined. Specifically, more number of companies defined less CGUs than defined more CGUs in the final sample.

Table 1 shows that about $14 \%$ companies in sample (12 of 86 firms) failed to disclose the number of CGUs. Although these companies stated that they used value in use to measure recoverable amount of CGUs, it was impossible to have goodwill impairment testing in this case because of no disclosure pertaining to number of CGUs.
Nearly $60 \%$ firms chose more than one CGU. There is a fact that, if number of defined CGUs increases, it is increasingly difficult to accept the validity of the risk homogeneity proportion pertaining to a single discount rate applied for all CGUs in the process of goodwill impairment testing. So the data in Table 1 provides evidence of the possibility that large listed companies chose inappropriate discount rates for all CGU assets employed in the process of goodwill impairment testing.

In case of immaterial goodwill, applying inappropriate discount rates is unlikely to substantially affect the economic decisions of financial users. However, generally it was evident that goodwill was material in the company sample. So using inappropriate discount rates would make more serious of reporting impairment losses and profits before tax. Because goodwill has potential affect to these misstatements.

Table 2: Company Goodwill Intensity by Sectors

\begin{tabular}{|l|l|l|l|l|l|l|l|l|l|}
\hline Sectors & No. of firms & \multicolumn{6}{|l|}{ Goodwill Intensity (Goodwill/Net Profit before tax) } \\
\hline & & & $<0$ & $\mathbf{0}$ to 1 & $\mathbf{1}$ to 2 & $\mathbf{2}$ to 3 & $\mathbf{3}$ to 4 & $\mathbf{4}$ to 5 & $>\mathbf{5}$ \\
\hline & & & & & & & & & \\
\hline Conglomerates & 3 & - & 3 & - & - & - & - & - \\
\hline Consumer Goods & 19 & - & 16 & 3 & - & - & - & - \\
\hline Energy & 2 & - & 2 & - & - & - & - & - \\
\hline Financials & 8 & - & 8 & - & - & - & - & - \\
\hline
\end{tabular}




\begin{tabular}{|l|l|l|l|l|l|l|l|l|}
\hline Industrial Goods & 8 & 1 & 7 & - & - & - & - & - \\
\hline Information Technology & 5 & - & 3 & 1 & 1 & - & - & - \\
\hline Materials & 4 & 1 & 3 & - & - & - & - \\
\hline Properties \& Construction & 10 & 1 & 8 & - & - & - & - & - \\
\hline Services & 20 & 3 & 12 & 2 & 2 & - & - & 1 \\
\hline Telecommunications & 1 & - & 1 & - & - & - & - \\
\hline Utilities & 6 & - & 5 & - & - & - & - & - \\
\hline & & & & & & & - \\
\hline TOTAL & $\mathbf{8 6}$ & $\mathbf{6}$ & $\mathbf{6 8}$ & $\mathbf{6}$ & $\mathbf{3}$ & - & - & $\mathbf{3}$ \\
\hline
\end{tabular}

Source: Authors' compilation

Goodwill intensity, one important variable, is a measure of the sensitivity of the reported profit to goodwill impairment expenses. Though the final sample, range of goodwill intensity was 26.54 with minimum value of -8.68 , maximum value of 17.86 , mean value of 0.56 and standard deviation value of 2.58. On average, goodwill balance as almost $56 \%$ as large as net profit before tax, suggesting that, to some extent, small proportion goodwill impairment could impact on profits before tax and have lower degree of sensitivity to a write down profit.
Table 2 illustrates that almost all companies have goodwill intensity values from 0 to 1 (about $70 \%$ total sample), about $7 \%$ companies have goodwill intensity value lower than 0 , another $7 \%$ with value from 1 to 2 , and small companies have values of goodwill intensity from 2 to 3 and higher 5 . Interestingly, no companies have goodwill intensity values in the range of 3 to 4 and 4 to 5 .

Table 3: Analysis of discount rate variance by sectors

\begin{tabular}{|c|c|c|c|c|c|c|}
\hline Sectors & No. of firms & $\begin{array}{l}>250 \quad \text { bps } \\
\text { below } \\
\text { expectation }\end{array}$ & $\begin{array}{l}150 \text { to } 250 \text { bps } \\
\text { below } \\
\text { expectation }\end{array}$ & $\begin{array}{l}\text { Within range } \\
(+/-150 \text { bps })\end{array}$ & $\begin{array}{l}150 \text { to } 250 \\
\text { bps above } \\
\text { expectation }\end{array}$ & $\begin{array}{l}>250 \quad \text { bps } \\
\text { above } \\
\text { expectation }\end{array}$ \\
\hline Conglomerates & 3 & 1 & - & 1 & - & 1 \\
\hline Consumer Goods & 19 & 6 & - & 7 & 2 & 4 \\
\hline Energy & 2 & 1 & - & - & - & 1 \\
\hline Financials & 8 & 3 & - & - & - & 5 \\
\hline Industrial Goods & 8 & 3 & 1 & 3 & - & 1 \\
\hline Information Technology & 5 & 2 & - & 1 & - & 2 \\
\hline Materials & 4 & 1 & - & 3 & - & - \\
\hline Properties \& Construction & 10 & 3 & - & 5 & - & 2 \\
\hline Services & 20 & 2 & 1 & 9 & 2 & 6 \\
\hline Telecommunications & 1 & & - & 1 & - & \\
\hline Utilities & 6 & - & 1 & 1 & 1 & 3 \\
\hline Total & 86 & 22 & 3 & 31 & 5 & 25 \\
\hline
\end{tabular}

Source: Authors' compilation

For investigating the variances between estimated and observed discount rates, the Table 3 shows the number of companies by the sectors and basic points based on expectations. Observed discount rates that fell into the range between minus $150 \mathrm{bps}$ and plus 150 bps within estimated discount rates were considered as falling in a reasonable expected range and thus there was no bias in the discount rate selections (Carlin and Finch, 2008). Outside the range "within expected +/-150 bps" was considered either below or above discount rate expectation and much or less it affects to the results of CGU recoverable amounts and impairment losses as well as reported profits.

More than one third companies disclosed the discount rates fell in the range of $+150 /-150$ bps expectation. More interestingly, of observed discount rates lay higher 150 bps from estimated values, the number of firms used discount rates higher than $150 \mathrm{bps}$ above expectation was slightly higher than that used observed discount rates higher than 150 bps below expectation. The number of the companies used observed discount rates higher than 250 bps above and below expectation is much higher than that used discount rates in the range of 150 to $250 \mathrm{bps}$ above and below expectation. This infers that there is high possibility that many companies used inappropriate discount rates and causes the recognition of reporting goodwill impairment charges into two opposite ways of misstatements (both overstatements and understatements).

Table 4: Discount Rate Variance and Goodwill Intensity (Value of Goodwill)

\begin{tabular}{|c|c|c|c|c|c|c|}
\hline $\begin{array}{l}\text { Goodwill Intensity } \\
\text { (GI) }\end{array}$ & $\begin{array}{l}>250 \text { bps below } \\
\text { expectation }\end{array}$ & $\begin{array}{l}150 \text { to } 250 \text { bps } \\
\text { below expectation }\end{array}$ & $\begin{array}{l}\text { Within expected } \\
\text { range }(+/-150 \mathrm{bps})\end{array}$ & $\begin{array}{l}150 \text { to } 250 \text { bps } \\
\text { above } \\
\text { expectation }\end{array}$ & $\begin{array}{l}>250 \text { bps } \\
\text { above } \\
\text { expectation }\end{array}$ & $\begin{array}{l}\text { Total } \\
\text { Goodwill (\$ } \\
\text { million) }\end{array}$ \\
\hline GI $>5(n=3)$ & - & - & 458.2 & $1,926.8$ & $2,854.0$ & $5,239.2$ \\
\hline
\end{tabular}




\begin{tabular}{|l|l|l|l|l|l|l|}
\hline From 4 to $5(\mathrm{n}=0)$ & - & - & - & - & - & - \\
\hline From 3 to $4(\mathrm{n}=0)$ & - & - & - & - & - & - \\
\hline From 2 to $3(\mathrm{n}=3)$ & - & 529.2 & $2,784.2$ & - & 169.8 & $3,483.3$ \\
\hline From 1 to $2(\mathrm{n}=6)$ & 652.6 & - & $1,260.8$ & $2,794.8$ & 241.3 & $4,949.7$ \\
\hline From 0 to $1(\mathrm{n}=68)$ & $3,138.7$ & 111.9 & $37,492.1$ & 81.6 & $7,427.3$ & $48,251.7$ \\
\hline Below 0 $(\mathrm{n}=6)$ & 35.3 & - & 901.8 & - & 2.3 & 939.5 \\
\hline & & & & & & \\
\hline TOTAL $(\mathbf{n}=86)$ & $\mathbf{3 , 8 2 6 . 7}$ & $\mathbf{6 4 1 . 2}$ & $\mathbf{4 2 , 8 9 7 . 3}$ & $\mathbf{4 , 8 0 3 . 3}$ & $\mathbf{1 0 , 6 9 4 . 9}$ & $\mathbf{6 2 , 8 6 3 . 6}$ \\
\hline
\end{tabular}

Source: Authors' compilation

If the company uses higher discount rate than appropriate one, there is high possibility to recognize recoverable amount of CGUs with lower values. The impact of the application by this way is to increase the likelihood that estimate of the CGU recoverable amount lowers CGU book values, and to increase the impairment losses and of course to reduce reporting profits. In this case, impairment charge would be overstated and reported profits would be understated.

In contrast, if the entity employs lower discount rate than its appropriateness, there is high likely to recognize CGU recoverable amount with higher values. Consequently, CGU recoverable amount may exceeds CGU book value, and to reduce impairment losses even though no impairment expenses, and apparently to increase reported earnings. By doing this way, impairment expense would be understated (potential goodwill impairment losses would be deferred in this period) and reported earnings would be overstated.

Of 42.9 billion goodwill balances had been tested for impairment testing using discount rates which fell into the reasonable range, one entity has goodwill of 33.9 billion, accounting for nearly $80 \%$ goodwill in this category, so explanation in this case must be conducted with high degree of care. If this case is considered to be the outlier, the percentage of goodwill reported by companies using discount rates higher than reasonable range must be much higher both above and below expectations. This is the case by explaining the consistent exercise of discretion and opportunistic behaviour of controlling reported profits among companies in the sample.

By understanding sectors, in 9 of 11 industry sectors (30 of 86 companies in total sample), a distinct majority of reported goodwill for impairment testing used discount rates higher than $150 \mathrm{bps}$ above expectations. Further in 9 of 11 sectors ( 25 of 86 companies in the whole sample), about $17 \%$ of goodwill by value had been impairment testing using discount rates in excess of 250 bps above expectations.

Table 4 reveals the discount rate variance data that is stratified by goodwill intensity score. Once again, data strengthens the small proportion of goodwill balances to be tested for impairment using discount rates in excess of expectations. It seems to be systematically the case that high percentage of goodwill in total fell into goodwill intensity of category from 0 to 1 (accounting for $76 \%$ in total goodwill). Companies that have different goodwill intensity categories (except categories of 3 to 4 , and 4 to 5) applying discount rates spread out of the range outside the reasonable range. However, goodwill value in the range of 150 bps above expectation was much higher than that in the range of $150 \mathrm{bps}$ below expectations. This means that the companies in sample have more motivations to overstate than understate discount rates. Consequently, impairment expenses were recorded overstatements and reported earnings were reported understatements.

Once again, if the CN Mobile's goodwill value of 33.93 billion within the reasonable range was considered to be the outlier, the value of goodwill reported by companies using discount rates higher than 150 bps above expectation was about 15.5 billion, accounting for $53.56 \%$ total goodwill in sample. This gave more evidence that impairment losses were overstated than understated and then reported profits were understated than overstated in the financial statements. So the picture of financial reports has been changed because of using incorrect discount rates in the process of testing goodwill impairments. That is why economic decisions of financial users may be affected, much or less, depending on the materiality of misstatements.

\section{Conclusion}

Goodwill, its impairment and its disclosure stated in the accounting standard are viewed as the most controversial themes of financial reporting both in techniques and practices. According to Hoogendoorn (2006), goodwill impairment testing and its disclosure are considered as two of five most difficult issues in practices when IFRS adoption has been made.

When applying method of value in use to calculate asset recoverable amounts, the selection of discount rates assumes to be one of the most material factors in the economic valuation model. Given the high reliance of discounted cash flow, discount rate is one of the central variables in deciding magnitude of impairment expenses under HKAS 36.

Testing the robustness of impairment testing under requirements of HKFRS, including HKAS 36 is a complicated task, requiring the matching array of issues including proper definition of CGUs, appropriate allocation of assets to CGUs, adoption of proper growth rates, selection of appropriate discount rates to transform future cash flows to its present value (Carlin \& Finch, 2008).

In terms of value in use adoption for calculating CGU recoverable amounts, prior research has provided evidence consistent with opportunism in the selection of disarray discount rates. Consequently, discount rate was disclosed either too high or too low than as it has, so the "true and fair" aspect of items in the financial statements has been much violated.

Unfortunately, by comparing independent estimated discount rates and observed discount rates of Hong Kong listed companies in the first year implementation of HKFRSs, the first year adoption of new standard, this study discovered that discount rates were more overstated than understated compared to the estimated ones. Above all others, opportunism behaviours in testing goodwill impairment have been revealed completely and result in more serious transparency of financial statements in general and goodwill impairment in particular.

Based on the empirical results of research, it is not easy to translate the idea into practice, at least right in this case. In testing goodwill impairment and calculating CGU recoverable amounts, if there is bias in the discount rate selection under the subjective ideas of management, no one can assure the real quality of reported profits, validity of valuation model. This produces concern issues 
to not only policy makers, financial users and also practitioners as well. That is why in the future policy issuance should be more details and put some more examples, even though some case studies in order to be easily applied by practitioners.

\section{Data Availability}

The data, mostly secondary data, was collected based on the sources have been cited and presented in the study and references. Authors can access the data online.

\section{Conflicts of Interests}

We - the authors declare that there is no conflict of interests regarding the publication of this paper.

\section{Funding Statement}

The research and publication of our article was funded by ourselves

\section{References}

[1] Carlin, T. M. and Finch, N., (2007), Early Impression of Australia's Brave New World of Goodwill Impairment. Macquarie Graduate School of Management (MGSM) Working Paper 1/2007.

[2] Carlin, T. M. and N. Finch (2008). Discount Rates in Disarray: Evidence on Flawed Goodwill Impairment Testing, University of Sydney and MGSM Centre for Managerial Finance, Working Paper.
[3] E\&Y (2008). International GAAP (2008). Generally Accounting Practice under International Financial Reporting Standards, John Wiley and Sons.

[4] Fernandez, P. (2003). Levered and Unlevered Beta, IESE Business School.

[5] Fernandez, P. (2008). The Equity Premium in 100 books, IESE Business School, Working Paper.

[6] Gameiro, I. M. (2008). "Equity Risk Premia Across Major International Markets." Economic Bulletin, 175186.

[7] Hoogendoorn, M. (2006). "International Accounting Regulation and IFRS Implementation in Europe and Beyond - Experiences with First-time Adoption in Europe." Accounting in Europe, 3.

[8] Hui, W.F., \& Ng, P.H. (2006). Accounting in Hong Kong: Regulatory Framework and Advanced Accounting Practice, School of Continuing and Professional Education.

[9] Lonergan, W. (2007). "AIFRS - A Practitioner's Viewpoint." The Journal of Applied Research in Accounting and Finance, 2(1), 9-19.

[10] Seetharaman, A., M. Balachandran,, \& Saravanan, A. (2004). "Accounting treatment of goodwill: yesterday, today and tomorrow." Journal of Intellectual Capital, 5(1), 131-152.

[11] Song, Z. (2007). "The Equity Risk Premium: An Annotated Bibliography." The Research Foundation of CFA Institute Literature Review, 1-18.

[12] Hamada, R. S., (1972), "The Effect of the firm's capital structure on the systematic risk of common stocks", Journal of Finance, 27, 435-452 